NBER WORKING PAPER SERIES

\title{
RATIONAL ADDICTION, PEER EXTERNALITIES AND LONG RUN EFFECTS OF PUBLIC POLICY
}

\author{
Donald S. Kenkel \\ Robert R. Reed III \\ Ping Wang
}

Working Paper 9249

http://www.nber.org/papers/w9249

\section{NATIONAL BUREAU OF ECONOMIC RESEARCH 1050 Massachusetts Avenue \\ Cambridge, MA 02138}

October 2002

The authors have benefitted from discussions with Mike Grossman and Casey Mulligan. The first and third authors acknowledge financial support from NIH/NIAAA grant no. 1R01-AA11657-01,02. The views expressed herein are those of the authors and not necessarily those of the National Bureau of Economic Research.

(C) 2002 by Donald S. Kenkel, Robert R. Reed III and Ping Wang. All rights reserved. Short sections of text, not to exceed two paragraphs, may be quoted without explicit permission provided that full credit, including (C) notice, is given to the source. 
Rational Addiction, Peer Externalities and Long Run Effects of Public Policy

Donald S. Kenkel, Robert R. Reed III and Ping Wang

NBER Working Paper No. 9249

October 2002

JEL No. D91, H20, I12

\begin{abstract}
$\underline{\text { ABSTRACT }}$
The main purpose of this research is to understand the patterns of consumption of addictive goods, their economic and welfare consequences for society and the long-run effect of tax policy in a dynamic general equilibrium model of rational addiction. In contrast to prior research, we allow individuals to make their consumption decisions simultaneous with savings and labor supply. When addictive goods have a stronger habit formation effect (an "addiction effect"), individuals choose to save less due to the anticipated adverse health consequences of addiction (a "detrimental health effect"). This is particularly important since total savings pins down future productivity in the economy. We also consider the role of peer influence in the choice of addiction and find that more "peer pressure" raises addictive consumption, lowers savings and reduces productivity. In light of the various distortions associated with addiction, we conclude by studying the long-run effects of an excise tax on addictive goods. Our calibration exercises suggest that incorporating capital formation and peer effects in a model of rational addiction are crucial for the design of public policy. In particular, accounting for peer externalities increases the optimal sin tax rate by more than 50 percent.
\end{abstract}

Donald S. Kenkel
Cornell University
Department of Policy Analysis
and Management
Ithaca, NY 14853
and NBER
dsk10@cornell.edu

Robert R. Reed III

University of Kentucky

Gatton College of Business

and Economics

Lexington, KY 40506

rrreed@uky.edu
Ping Wang

Vanderbilt University

Department of Economics

415 Calhoun Hall

Nashville, TN 37235

and NBER

ping.wang@vanderbilt.edu 


\section{Introduction}

In recent years, social scientists, health care professionals, and policymakers have devoted much effort towards studying the patterns of consumption of addictive goods and their consequences for society. This is particularly important since these substances have serious short-term and longterm effects, at both the individual and social level. From an individual's perspective, because addiction is an acquired habit, the associated costs of consumption are long-lasting. In addition, addictive goods are harmful to one's health, possibly leading to a shorter lifespan. ${ }^{1}$ This aspect of addiction deserves attention since the long-term consequences of an individual's unhealthy behavior will affect their savings and investment decisions. ${ }^{2}$

Many of the costs of participation in the consumption of addictive goods, however, will extend beyond an individual. In particular, the social costs from addictive goods will be borne both in the short and the long term. The short-term effects from consumption of addictive goods are directly apparent in a number of ways. For example, many studies have shown that there are large

${ }^{1} \mathrm{~A}$ number of studies have demonstrated the detrimental health effects resulting from addiction. Manning et al (1991) document many of the adverse health consequences of smoking and alcohol consumption. See also Cook (1981), Cook and Tauchen (1982), and Cook and Moore (1999) who document that higher state liquor excise taxes are associated with lower state mortality rates.

${ }^{2}$ The evidence on the effects of addiction on financial savings and investment appears to have received only limited attention. However, in somewhat related work by Bloom, Canning, and Graham (2002), they show that countries with higher life expectancies tend to have higher savings rates. In contrast to financial investment, there is a wide array of evidence on the implications of alcohol consumption for reduced human capital investment. Mullahy and Sindelar (1993) find that heavy drinking in high school is associated with a lower average number of years of schooling completed following high school. See also Mullahy and Sindelar $(1989,1991)$ and Cook and Moore $(1993,1999)$ for discussion on the relationship between alcohol consumption and schooling and Kenkel and Wang (1999) for the effects of alcohol consumption on job selection. 
external costs associated with alcohol consumption, mostly the result of drunk driving. ${ }^{3}$ In addition, much evidence suggests that alcohol consumption affects the incidence of child abuse, the homicide rate, and other forms of violent activity. ${ }^{4}$ Furthermore, there are also long-term external costs associated with addiction due to their adverse health effects. These costs are external since individuals with poor health are more likely to receive government assistance. ${ }^{5}$ Finally, an important aspect is that in many cases, consumption of addictive goods takes place in social settings, where peer influence is likely to be important. ${ }^{6}$ Thus, for a host of reasons, the social costs of addiction

${ }^{3}$ As reported in Cook and Moore (1999), the U.S. Center for Disease Control estimated that 105,000 deaths in 1987 were alcohol-related. Manning et al (1989) estimate that the total property damage from alcohol-related motor vehicle accidents was approximately $\$ 3.6$ billion in 1983. Kenkel (1993) reports that alcohol-related traffic accidents resulted in 24,000 deaths and over 554,000 injuries in 1986. For the year 1986, he finds the total value of deaths and injuries of victims resulting from drunk driving to be $\$ 17.6$ billion. There are also sizable external costs resulting from smoking. The U.S. Center for Disease Control estimates that 2,400 deaths occur each year due to the consumption of second-hand smoke. In addition, Manning et al (1989, 1991) find that there are significant external costs from smoking because of property loss. In particular, they estimate the property loss from smoking-related fires was approximately $\$ 340$ million in 1983.

${ }^{4}$ Cook and Moore (1993b, 1999) find that alcohol consumption is related to the rate of domestic violence. They show that per capita consumption is associated with higher rates of rape, aggravated assault, and robbery, and homicide. Markowitz and Grossman (2000) show that higher beer taxes may lower the lower the amount of child abuse. See also Reiss and Roth (1993).

${ }^{5}$ Rice (1990) documents that alcoholics receive a high share of government assistance due to higher receipts for medical care, disability payments, and social security. Manning et al $(1989,1991)$ estimate that $\$ 3.1$ billion was spent to finance the criminal justice system and $\$ 54$ million was allocated towards funding social programs as the result of alcohol abuse in 1983. They find, however, that the external costs of smoking are offset by excise taxes on cigarettes. Furthermore, Viscusi (1995) finds that smokers generate net external benefits for society as a result of their increased mortality.

${ }^{6}$ A number of studies have documented the role of peer influence in the participation of consumption of addictive goods. Norton et al (1998) find that a $10 \%$ point increase in the rate of peer drinking is associated with an equal increase in the probability that an individual will choose 
may far exceed the private costs.

In order to better understand how public policy should be designed in light of both the internal and external consequences of addiction, this paper constructs a dynamic general equilibrium model of rational addiction. We study the intertemporal decisions concerning non-addictive and addictive goods consumption. As a first step towards understanding the social ramifications of addiction, we allow individuals to make their consumption decisions simultaneous with savings and labor supply. This is essential since aggregate savings by the young in our economy pins down the capital stock to be utilized by workers in the following period. These choices have obvious general equilibrium effects as they affect total production in each sector of the economy, wages, interest rates, and relative prices of addictive to non-addictive goods.

We next briefly outline the important details of our benchmark model. We construct a twoperiod overlapping generations model with rational addiction. Individuals when young make choices concerning consumption (of both types of goods) and savings, whereas old agents simply consume. There are three types of goods in the economy: a composite (non-addictive) good, an addictive good, and capital. We assume: (i) capital and the composite good are homogeneous and (ii) production in the composite goods sector is capital intensive while the addictive goods sector is labor intensive. Total savings by the current young pins down the capital stock in the economy the following period.

to drink. They also find that peer influence plays an important role in youth smoking behavior. DeCicca, Kenkel, and Mathios $(2000,2002)$ study the role of peer acceptance as an important determinant of youth smoking behavior. In particular, they point out that there may be differences in the links between the decision to smoke and peer acceptance across different racial and ethnic groups. Parental drinking and smoking also affect drinking and smoking decisions of children. Jones (1994) and Yen and Jones (1996) show that smoking by an adult household member increases the likelihood of an individual adult's decision to smoke. See also the discussion in Baumann and Ennett (1996), Beales (1996), Cook and Moore (1999), and Laux (2000). 
Consumption decisions when young have important long-term implications - current consumption of the addictive good raises the marginal utility of addictive consumption when old (an addiction effect), but also lowers overall utility in the future due to a detrimental health effect. Since individuals make consumption and savings choices simultaneously, an individual's choice of addiction has external consequences - they will save less and the capital stock to be utilized by the future generation will be lower. In particular, we show that the pattern of habit formation has a significant influence on the equilibrium allocation. For example, when addictive goods have a stronger habit formation effect, total demand for the addictive good rises since a given amount of consumption when young further increases the marginal utility of addictive consumption when old. Due to a detrimental health effect, the higher stock of the addictive good implies that individuals derive less utility from old-age consumption. Consequently, individuals save less and the capital stock to be utilized by the future generation will be lower.

In a second model, we incorporate the role of peer influence in addictive behavior and the external consequences of an individual's consumption. As has been emphasized by a number of studies, peer effects are important for participation in addiction. We capture these aspects by assuming the total stock of addictive consumption raises the marginal utility of addictive substances. That is, when total consumption of addictive goods in the economy is higher, an individual will obtain higher marginal utility from his own consumption. Thus, our model shows how peer influence plays an important role in total consumption of addictive substances in the economy. Furthermore, we also capture some of the negative external consequences of addiction by asserting that there is an increase in the rate of mortality when there is more consumption of the addictive good in society. That is, we assume that old-age individuals derive lower overall utility when 
society's addictive stock is higher. This is meant to represent some of the external consequences associated with consumption of addictive goods such as the possibility of drunk driving or the consumption of second-hand smoke. Importantly, we show that when peer influence plays a stronger role in addictive habit formation, total consumption of the addictive good is higher and total savings in the economy is lower. The reduction in total savings occurs because individuals obtain less utility from old-age consumption. ${ }^{7}$

We proceed to studying the long-run effects of an excise tax on addictive goods. We note that there are a number of important reasons for taxation of addictive consumption in our framework. When individuals are young and make their savings decisions, they do not take into account how a lower capital stock will affect productivity in the future in the economy. Further, when peer influence plays an important role in addictive behavior, individuals do not take into account that their consumption will increase society's taste for addiction and how it also contributes negatively to overall utility in the economy. Finally, it is also important to note that excise taxes (both state and federal) are an important source of government revenue. Our dynamic general equilibrium model is important in that we are able to capture both the consequences of excise taxation on habit formation in the economy (consumption by both the young and old), but also the overall level of tax revenues. ${ }^{8}$ Our results are especially significant since we show that a tax on addictive consumption

${ }^{7}$ In this manner, we suggest that in many cases addictive goods may be examples of commodities which exhibit Leibenstein's (1950) "bandwagon effects" or "snob effects." In his work, demand for a commodity illustrates a bandwagon effect when "...the demand for a commodity is increased due to fact that others are consuming the same commodity." In contrast to Leibenstein, we focus explicitly on addictive consumption and describe the role of policy in light of its negative external consequences in a dynamic general equilibrium framework.

${ }^{8}$ There is an empirical literature studying how a sin tax may deter alcohol consumption and reduce the underlying social costs; see, for example, Kenkel (1996) and Pogue and Stontz 
will affect the overall level of capital formation in the economy and thereby relative prices. Interestingly, our numerical results suggest that incorporating peer externalities in the formation of addiction will significantly affect the optimal tax rate.

The remainder of the paper is organized as follows. In Section II, we describe the basic economic environment. In Section III, we present our equilibrium concept and solution algorithm. In Section IV, we demonstrate the results of our benchmark model through some numerical exercises. Section V extends our benchmark model to the case of peer externality effects of addictive behavior. Section VI consider the possible effects of public policy through a tax on the addictive good. Section VII concludes and discusses extensions for future research.

\section{The Basic Economic Environment}

In this section, we begin by considering a simple perfect foresight economy where agents of overlapping generations live for two periods (the young and the old age). There is no uncertainty in this environment or sources of private information. The economy consists of two types of goods, an addictive good and a composite non-addictive good. We let the composite good be the numeráire and denote $p_{t}$ as the relative price of the addictive good in terms of the composite good in period $t$. The equilibrium concept we utilize is a steady-state competitive equilibrium where individuals take prices as given and product markets clear each period.

In the first period of life, individuals work, save, and consume. Old agents simply consume. We use superscripts to index the generation and subscripts to index the time period. Thus, $c_{t}^{t}$ and $c_{t+1}^{t}$ denote the consumption of the composite good in period $t$ and $t+1$, respectively, by a representative individual from generation $t$. Similarly, $a_{t}{ }_{t}^{t}$ and $a_{t+1}^{t}$ denote the consumption levels of the additive

(1989), respectively. 
good by a member of generation $t$ in periods $t$ and $t+1$. Consumption of the addictive good contributes to an individual's stock of the addictive good in the following period. Letting $S_{t+1}^{t}$ denote the stock of the addictive good of a member of generation $t$ in period $t+1$, we have $S_{t+1}^{t}=a_{t}{ }^{t}$.

\section{II.A. Preferences}

To illustrate how consumption of both the addictive and non-addictive composite goods generate utility for agents, we seek to capture two aspects associated with participation in the consumption of addictive substances. The first is that addiction can be regarded as a particular form of habit formation - when individuals have consumed more of a particular addictive good in the past, their current consumption of the good will be higher. More precisely, past and current consumption of the addiction good are intertemporal complements. Another is to account for the adverse health consequences associated with addiction. In particular, we model that individuals will be less healthy when old as a result of having consumed more of the addictive good in their youth. That is, we consider that old-age individuals will obtain less overall utility when their addictive stock is higher. This is usually referred to as the conventional addiction effect in the literature.

Under this setting, an agent born at date $t$ has a lifetime utility function:

$$
\Omega=u\left(c_{t}^{t}, a_{t}^{t}\right)+\frac{1}{1+\rho} v\left(S_{t+1}^{t}\right) u\left(c_{t+1}^{t}, a_{t+1}^{t}\right)
$$

where $\rho>0, v^{\prime} \geq 0$ and $v^{\prime \prime} \geq 0$. In addition, an agent's periodic utility function takes the constant

elasticity form: $\frac{\left(c^{\alpha} a^{1-\alpha}\right)^{1-\sigma}}{1-\sigma}$, where $0 \leq \alpha \leq 1$ and $\sigma>1$. The latter condition limits the degree of intertemporal substitution (measured by $1 / \sigma$ ), which is frequently imposed in the life cycle literature. It may be noted regarding the cardinality property of this periodic utility functional form, its value is always negative. Given these preference specifications, it is easily shown that utility is increasing 
in both the consumption of the addictive and non-addictive (composite) goods. We also note that $v\left(S_{t+1}^{t}\right)$ represents a detrimental health effect associated with addictive consumption - when an individual's addictive stock is higher, $v\left(S_{t+1}^{t}\right)$ is higher and therefore agents will derive less lifetime utility from old-age consumption (recall that $u$ is negative). Additionally, the conventional addiction effect is present. That is, one can show that the marginal utility of current consumption of the addictive good is increasing in the amount of past consumption of the addictive good (recall that $S_{t+1}^{t}=a_{t}^{t}$ ). For tractability, we assume that $v=v\left(S_{t+1}^{t}\right)=1+v_{0}\left(S_{t+1}^{t}\right)^{\eta}$. By construction, perfect foresight implies that agents are rational addicts in the sense that anticipated changes in the marginal valuation or relative price of future consumption of the addictive good affect current consumption (cf. Becker and Murphy 1988).

It may be noted that due to the presence of the detrimental health effect that depends on the previous consumption of the addictive good, $\rho$ is no longer the exact measure of the rate of time preference. Based on the standard Fisherian framework, the rate of time preference is defined as the ratio of the current to future marginal utilities (evaluated at the steady state) minus one. Yet, the detrimental health effect will bring in an asymmetry between the two goods. In view of the nonaddictive good, the rate of time preference is: $\frac{1+\rho}{v(a)}-1$; in view of the addictive good, it becomes: $\frac{1+\rho}{v(a)}\left[1-\frac{\epsilon_{v}}{(\sigma-1)(1-\alpha)}\right]-1$, where $\epsilon_{v}=a v^{\prime} / v \geq 0$ denotes the marginal utility elasticity of the addictive stock. While in either case the detrimental health effect is mixed with time preferences, the latter measure is smaller than the former. Intuitively, with the consideration of the detrimental health effect from current consumption of the addictive good, agents are more patient, giving less preference toward current consumption. 


\section{II.B. Technology}

There are two separate production technologies for the non-addictive composite good and the addictive good sectors. Production in the composite good sector requires both capital and labor. Its total production in period $t$ is $y_{t}$ follows a Cobb-Douglas technology:

$$
y_{t}=A\left(k_{t-1}^{t-1}\right)^{\theta}\left(l_{t}^{t}\right)^{1-\theta}
$$

where $\theta$ denotes the capital intensity of the composite goods sector. For tractability, the addictive good sector only requires labor for production and its output $x_{t}$ has the following production technology:

$$
x_{t}=B\left(1-l_{t}^{t}\right)
$$

where $B>0$ is the scaling factor of addictive good production. In essence, the asymmetry between the production technologies restricts that the composite good sector is more capital intensive than the addictive good sector. ${ }^{9}$

\section{II.C. Budget Constraints}

Individuals (of generation $t$ ) only work in the first period of their lives, receiving a wage income $w_{t}$. Individuals do not work in the second period, though they desire to consume in both periods. Thus, they must save and provide capital to the composite good sector when old. Noting that $p_{t}$ is the relative price of the addictive good in terms of the composite good, a member of the young generation in period $t$ faces the following budget constraint in the first period of life:

$$
p_{t} a_{t}^{t}+c_{t}^{t}+k_{t}^{t}=w_{t}
$$

${ }^{9}$ It also implies that the capital stock affects overall productivity in the economy more than the addictive sector. 
This implies that the wage income of an individual when young can be used for consumption and saving (in forms of capital). In turn, denoting the "gross" rate of (real) interest as $R_{t+1}$, the agent's budget constraint in the second period is:

$$
p_{t+1} a_{t+1}^{t}+c_{t+1}^{t}=R_{t+1} k_{t}^{t}
$$

Combining the periodic budget constraints (3a) and (3b), the individual's intertemporal budget constraint is thus given by:

$$
p_{t} a_{t}^{t}+c_{t}^{t}+\frac{1}{R_{t+1}}\left(p_{t+1} a_{t+1}^{t}+c_{t+1}^{t}\right)=w_{t}
$$

\section{Equilibrium}

Our equilibrium concept is straightforward. We study steady-state equilibria where all variables are constant over time, the product and factor markets clear each period, and agents make choices to maximize their lifetime utility. In each generation, a representative young agent chooses a level of consumption of both types of goods taking prices as given.

\section{III.A. Market Clearance and Price Determination}

Both the product and factor markets are standard Walrasian markets. The two material balance conditions which represent equilibrium in each product market are:

$$
\begin{gathered}
k_{t}^{t}+c_{t}^{t-1}+c_{t}^{t}=y_{t} \\
a_{t}^{t-1}+a_{t}^{t}=x_{t}
\end{gathered}
$$

Equation (4a) states the total output of the composite good at period $t$ must be equal to aggregate 
consumption (by both the young and the old) and capital investment. Since the addictive good is non-storable, its material balance condition is of a simple form as in (4b). These conditions will help determine the endogenous relative price of the addictive good in general equilibrium.

Factor market efficiency determines the equilibrium wage rate and the equilibrium interest rate. By free mobility of labor across the composite and addictive goods sectors, we have the following wage equalization equation (across the two sectors):

$$
F_{l_{t}}\left(k_{t-1}^{t-1}, l_{t}^{t}\right)=p_{t} B
$$

Labor efficiency immediately leads to:

$$
p_{t} B=w_{t}
$$

Finally, the rental rate under capital efficiency implies:

$$
R_{t}=F_{k}\left(k_{t-1}^{t-1}, l_{t}^{t}\right)
$$

\section{III.B. Optimization Conditions}

In this setting, a representative member of the young generation chooses a vector of consumption choices of both types of goods throughout his entire lifetime $\left(c_{t}^{t}, a_{t}^{t}, c_{t+1}^{t}, a_{t+1}^{t}\right)$ in order to maximize lifetime utility (given by equation (1)) subject to the intertemporal budget constraint, (3c).

The following are the first-order conditions for a member of generation $t$ in his objective of maximizing lifetime utility:

(i) (atemporal efficiency for young age) 


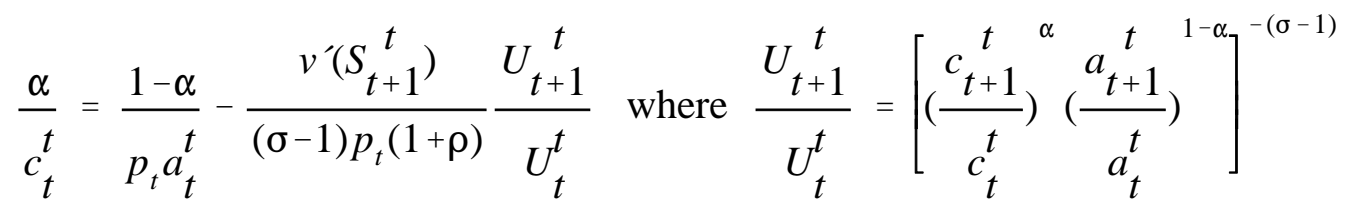

(ii) (atemporal efficiency for old age)

$$
\frac{c_{t+1}^{t}}{p_{t+1}^{t} a_{t+1}^{t}}=\frac{\alpha}{1-\alpha}
$$

(iii) (intertemporal efficiency for composite good)

$$
\frac{U_{t+1}^{t}}{U_{t}^{t}} \frac{R_{t+1}}{1+\rho} v\left(S_{t+1}^{t}\right)=\frac{c_{t+1}^{t}}{c_{t}^{t}}
$$

(iv) (intertemporal efficiency for addictive good)

$$
\frac{p_{t+1} a_{t+1}^{t}}{p_{t} a_{t}^{t}}\left[1-\frac{\epsilon_{v, t+1}^{t}}{R_{t+1}(1-\alpha)(\sigma-1)} \frac{c_{t+1}^{t}}{c_{t}^{t}}\right]=\frac{c_{t+1}^{t}}{c_{t}^{t}}
$$

On the one hand, (6a) and (6b) equates the atemporal marginal utilities between consuming the composite and the addictive goods for the young and the old, respectively. On the other, (6c) and (6d), respectively, govern intertemporal efficiency for consumption of the composite and the addictive goods over time. In both atemporal efficiency for the young and intertemporal efficiency for composite-good consumption, the detrimental health effect enters, influencing an individual's optimal decision. Moreover, the intertemporal efficiency for addictive-good consumption takes into account not only the detrimental health effect, but also the conventional addiction effect via the marginal utility elasticity of the addictive stock, $\epsilon_{v}$. 


\section{III.C. Definition of Steady-State Equilibrium}

We now define the equilibrium in the steady state in the sense that

$$
c_{t}^{t-1}=c_{t+1}^{t}=c^{\prime} ; a_{t}^{t-1}=a_{t+1}^{t}=a^{\prime} ; k_{t-1}^{t-1}=k_{t}^{t}=k
$$

Definition 1: (Steady-State Equilibrium) A steady-state equilibrium is a list of quantity and price variables $\left\{c_{t}^{t-1}, a_{t}^{t-1}, c_{t}^{t}, c_{t+1}^{t}, a_{t}^{t}, a_{t+1}^{t}, p_{t}, p_{t+1}, R_{t+1}, k_{t-1}^{t-1}, k_{t}^{t}, l_{t}^{t}, w_{t}\right\}$ satisfying:

(i) individual optimization: (3b), (3c), (6a)-(6d);

(ii) goods market equilibrium: (4a), (4b) (with (2a) and (2b) being substituted in);

(iii) factor market equilibrium: (5a)-(5c);

(iv) steady state: (7).

Individual optimization includes: (i) budget constraints (3b) and (3c); (ii) atemporal efficiency for young and old ages, respectively, (6a) and (6b); and, (iii) intertemporal efficiency for the composite and the addictive goods, respectively, (6c) and (6d). Goods market equilibrium contains the two material balance conditions, (4a) and (4b), after substituting the production technologies, (2a) and (2b). Factor market equilibrium is summarized by wage equalization, (5a), and labor and capital efficiency, (5b) and (5c).

Thus, at this point, it appears as if we have a system of 14 equations with only 13 endogenous variables. This means that either the system is over-determined or one of the equations is redundant. Note that there are five endogenous variables under the individual's control: demand for the composite good when young, demand for the addictive good when young, savings, demand for the composite good when old, and demand for the addictive good when old. Yet there are potentially six equations to pin these down: (3b), (3c), and (6a)-(6d). However, one can easily show that one 
of these equations is redundant, which is indeed the residual savings argument in overlapping generations. In the analysis below, we will omit equation (6d) to avoid redundancy as well as system singularity.

\section{III.D. Solution Algorithm}

The steady-state equilibrium solution algorithm of the $13 \times 13$ system is elaborated in the following 6 steps.

Step 1. Impose steady-state conditions.

By imposing steady-state conditions (7) on the system renders a total of 10 endogenous variables: $c, c^{\prime}, a, a^{\prime}, p, p^{\prime}, R, k, l$, and $w$, which are determined by the remaining 11 equations: (3b), (3c), (4a), (4b), (5a)-(5c), and (6a)-(6d).

\section{Step 2. Prove price equalization.}

We note that in each time period markets always clear. In the steady-state, all variables are constant across time. This immediately implies that prices must be the same over time so that $p=p^{\prime}$. Therefore, our system is now composed of only 9 endogenous variables and 10 equations.

Step 3. Solve for output and the labor allocation; show that Walras' law holds.

Since the system has only 9 endogenous variables but 10 equations, the system is either overdetermined or one of the equations in the system is redundant. In fact, we can simply employ the Walras law argument to show that if the other equations in the system are satisfied, then the intertemporal budget constraint automatically holds. To undertake this task, we first solve for output and the allocation of labor by using the production technology (2a), the second period budget constraint (3b), the wage equalization condition (5a) and the capital efficiency condition (5c) (see the Appendix): 


$$
\begin{gathered}
y=\frac{\left(c^{\prime}+p a^{\prime}\right)}{\theta} \\
x=B-\frac{(1-\theta)}{\theta p}\left(c^{\prime}+p a^{\prime}\right) \\
l=\frac{(1-\theta)}{\theta} \frac{\left(c^{\prime}+p a^{\prime}\right)}{p B}
\end{gathered}
$$

Thus, total production of both goods, $y$ and $x$, and the allocation of labor, $l$, are now expressed in terms of $\left\{c^{\prime}, p, a^{\prime}\right\}$. Substitute these into the material balance conditions for the composite and the addictive goods in conjunction with the capital efficiency condition $(5 \mathrm{c})$ then yields the intertemporal budget constraint (3c). Therefore, the intertemporal budget constraint is redundant as long as the second period budget constraint, the production technology for the composite good, the wage equalization condition, the capital efficiency condition, the material balance conditions, and the labor efficiency condition all hold simultaneously.

Summarizing, we have a system of 9 linearly independent equations solving for the 9 endogenous variables: $\left\{c, c^{\prime}, a, a^{\prime}, p, R, k, l, w\right\}$. The entire system consists of the second period budget constraint, (3b), the material balance conditions (4a) and (4b), the production factor efficiency conditions (5b) and (5c), the wage equalization condition (5a), as well as three consumer optimization conditions (6a)-(6c), all imposing steady state.

Step 4. Express the system in a recursive manner to reduce to a $3 \times 3$ subsystem.

In order to reduce to an analytically manageable system, we next express $\{R, k, l, w\}$ in terms of $\left\{c, c^{\prime}, a, a^{\prime}, p\right\}$, by utilizing (3b) and (5a)-(5c) (imposing steady-state). This would reduce to a $5 \times 5$ subsystem in $\left\{c, c^{\prime}, a, a^{\prime}, p\right\}$. This is accomplished by utilizing the production technology (2a), as well as labor and capital efficiency conditions (5b) and (5c), to derive: 


$$
R=\theta A^{\frac{1}{\theta}}{\frac{1-\theta^{\frac{1-\theta}{\theta}}}{\theta p B}}^{\frac{1}{\theta}}=R(p)
$$

This implies that capital rental $R=R(p)$ is a decreasing function of the relative price of the addictive good, An immediate consequence is that $w=w(p)$ where $\mathrm{d} w / \mathrm{d} p>0$ by the labor efficiency condition (5b) in the steady-state and moreover, the capital-labor ratio can also be written as a positive function of the relative price $p$ alone. These results are driven by the fact that capital is used more intensively in composite good production, which are straightforward applications of the Stolper-Samuelson Theorem in trade theory.

Then, by the second period budget constraint (3b), we have: $R(p) k=c^{\prime}+p a^{\prime}$, or, equivalently,

$$
k(p)=\frac{c^{\prime}+p a^{\prime}}{R(p)}
$$

Thus, $k$ is expressed as a function of $\left\{c^{\prime}, a^{\prime}, p\right\}$, that is, the savings behavior is tied to future consumption and the relative price. By utilizing these relationships, our subsystem now consists of five endogenous variables $\left\{c, c^{\prime}, a, a^{\prime}, p\right\}$ to be determined by the five remaining equations, (4a), (4b) and (6a)-(6c) (imposing steady-state).

Furthermore, the material balance condition for the composite and the addictive goods, (4a) and (4b), can be used to solve for $c^{\prime}$ and $a^{\prime}$ in terms of $\{c, a$, and $p\}$ (see the Appendix),

$$
\begin{gathered}
c^{\prime}=\frac{p(B-a)(R-\theta)-R c}{\theta} \\
a^{\prime}=\frac{\theta p(B-a)-(1-\theta) R[p(B-a)-c]}{\theta p}
\end{gathered}
$$

It is seen from these expressions that the demand curves for both types of goods among old-age 
individuals are downward-sloping.

Finally, the three remaining first-order conditions (6a)-(6c), together with (11a) and (11b), jointly determine the endogenous variables $(c, p, a)$ in the following $3 \times 3$ subsystem (see the Appendix):

$$
\begin{gathered}
\frac{c}{p}=(B-a)\left[1-\frac{\tilde{\theta}}{R(p)}\right] \\
\left(\frac{1-\alpha}{\alpha a} \frac{c}{p}\right)^{1+\alpha(\sigma-1)} a^{\sigma} R(p)\left[1+v_{0} a^{\eta}\right]=(1+\rho)\left[(B-a)-\frac{1-\theta}{\theta} R(p)\left(B-a-\frac{c}{p}\right)\right]^{\sigma} \\
\eta v_{0}\left[(B-a)(R(p)-\theta)-R(p) \frac{c}{p}\right]=\alpha \theta\left[\frac{1-\alpha}{\theta a} \frac{c}{p}-1\right](\sigma-1) R(p)\left(1+v_{0} a^{\eta}\right) a^{1-\eta}
\end{gathered}
$$

where $\tilde{\theta}=\theta /(1-\alpha \theta)$.

Step 5. Construct the fixed-point mapping in $a$ to pin down its steady-state equilibrium value.

This is accomplished by first substituting the ratio $c / p$ from (12b) and (12c) using (12a), which yields the following expressions:

$$
\begin{gathered}
\left(\frac{1-\alpha}{\alpha}(B-\alpha)\left[1-\frac{\tilde{\theta}}{R(p)}\right]\right)^{1+\alpha(\sigma-1)} a^{(1-\alpha)(\sigma-1)} R(p)\left(1+v_{0} a^{\eta}\right)=(1+\rho)[\tilde{\theta}(1-\alpha)(B-a)]^{\sigma} \\
\left(\frac{(1-\alpha)}{\alpha a}(B-a)[R(p)-\tilde{\theta}]-R(p)\right)(\sigma-1)\left(1+v_{0} a^{\eta}\right) a^{1-\eta}=\eta v_{0} \tilde{\theta}(B-a)
\end{gathered}
$$

which are only in terms of $\{p, a\}$. It is easily seen that (13b) is linear in $R(p)$, from which we can solve for $R(p)$ in terms of $a$, 


$$
R(p)=\frac{\frac{\eta v_{0} \tilde{\theta}(B-a)}{(\sigma-1)\left(1+v_{0} a^{\eta}\right) a^{1-\eta}}+\tilde{\theta} \frac{1-\alpha}{\alpha} \frac{B-a}{a}}{\frac{1-\alpha}{\alpha} \frac{B-a}{a}-1}
$$

In turn, the fixed-point mapping in $a$ is obtained by substituting (14) into (13a). Since the expression is highly nonlinear in $a$, we are unable to offer a general existence proof for a steady-state equilibrium in the economy. We can, however, solve for the steady-state values in the economy numerically. As we describe below, we find that the existence of a steady-state equilibrium in our economy is robust under a set of plausible parameters.

Step 6. Recursively substitute to obtain the steady-state equilibrium values for other variables.

By Step 5, the steady-state equilibrium value of $a$, denoted $a_{s}$, is obtained. We then substitute $a_{s}$ into (14) to yield $R_{s}$ and by (9), we obtain $p_{s}$. Next, substitution of $\left\{a_{s,} R_{s,} p_{s}\right\}$ into (12a) yields $c_{s}$, whereas substitution of $\left\{a_{s}, R_{s,} p_{s}, c_{s}\right\}$ into (11a) and (11b) gives $c_{s}{ }^{\prime}$ and $a_{s}{ }^{\prime}$. By plugging $\left\{p_{s}, c_{s}{ }^{\prime}, c_{s}{ }^{\prime}\right\}$ into (8a)-(8b) and (10), the steady-state equilibrium values of $\left\{y_{s}, l_{s}, x_{s}, k_{s}\right\}$ are determined.

\section{Numerical Experiments in the Benchmark Model}

It is useful to begin by classifying the parameters in the benchmark model. First, the parameters $\alpha$ and $\sigma$ affect individuals' instantaneous utility from current consumption while $v_{0}$ and $\eta$ reflect the influence of addiction on old-age utility. Second, $A, B$, and $\theta$ represent technology in each sector of the economy. Finally, $\rho$ reflects the rate at which individuals discount old-age utility keeping constant the health component. We choose the following set of parameters as a benchmark for our numerical results: $\eta=1.3, v_{0}=0.5, B=3, \theta=0.4, \alpha=0.775, \sigma=2, A=4$, and $\rho=0.035$. The 
selection of the intertemporal elasticity of substitution $(1 / \sigma)$, the non-health component of the time preference rate $(\rho)$ and the output elasticity of capital $(\theta)$ are basically consistent with standard neoclassical models (the output elasticity of capital is on the high side due to the setup that capital is used only in the composite good sector). The remaining 5 parameters are chosen based on the following criteria: (i) the real interest rate is at $6 \%$, (ii) the employment share of the non-addictive composite good sector is about $80 \%$, (iii) the output share of the non-addictive composite good sector falls into the range of $85-90 \%$ (recall that capital is used only in the composite good sector), (iv) the wage income share $(w /[p x+y])$ is about $65 \%$, and (v) the steady-state consumption ratio $c_{s}{ }^{\prime} / c_{s}$ is around one (by normalization).

Starting from our benchmark set of parameters, we change the value of each one individually in order to understand how each factor affects the steady-state equilibrium. We begin by describing the implications of the addiction parameters $\left(\eta\right.$ and $v_{0}$ ). We note that $v_{0}$ and $\eta$ have two separate influences on old-age utility - an increase in $v_{0}$ does not affect the elasticity of $V$ with respect to $S$ while $\eta$ does. In this sense, we may view $v_{0}$ as a parameter that emphasizes the detrimental health effect while $\eta$ highlights the (conventional) addiction effect associated with past consumption of the addictive good.

\section{(Insert Table 1 about here)}

The distinct effects are clearly present in our numerical results. We begin by describing the general equilibrium implications of the addictive effect. We note that for a given addictive stock, higher values of $\eta$ are associated with higher marginal utility from consumption of the addictive good when old. Thus, we find that in economies where the addictive effect is stronger, the total demand (and consequently consumption of) for addictive goods is higher. Due to the detrimental 
health effect associated with consumption of addictive goods, individuals will discount old-age utility more. Since the future is less important, the young choose to save less and consequently, the next generation will receive a lower capital stock. Interestingly, since there is less capital formation in the economy, total production of the composite good will be lower when there is a stronger addictive effect. Thus, although total demand for the addictive good is higher, its relative price will be lower. Since individuals save less, consumption of both types of goods will be lower when individuals become old. The lower capital stock also implies that wages will be lower since the marginal product of labor in the composite goods sector is lower. ${ }^{10}$

We turn to a consideration of how the adverse health consequences resulting from addiction (the detrimental health effect) affect the equilibrium allocation in our economy. First, we re-iterate how we capture the detrimental health effect resulting from consumption of addictive goods. When addiction has more severe health consequences ( $\mathrm{v}_{0}$ higher), individuals will obtain less overall utility in their old age. However, due to consumption smoothing, agents will have a preference to be able to consume both types of goods in the second period of their lives. Thus, when addiction has more severe health consequences, we find that total consumption of addictive goods will be lower, as well as the relative price. This occurs because young forward-looking individuals in their objective of maximizing lifetime utility choose to consume less of the addictive good so as to conserve on the

\footnotetext{
${ }^{10}$ Our results imply that individuals who anticipate having poor health when old will choose to save less. We do not, as in Grossman (1972), allow individuals to be able to purchase medical care when old to offset the loss from addiction. Upon extending our model to include a medical sector, it may be possible that the addictive effect would lead to more savings. Since the medical sector would be capital intensive, productivity in the composite goods sector is likely to be lower when the addictive effect is stronger. Furthermore, Starr-McCluer (1996) finds that individuals with good health tend to have higher amounts of savings. This evidence provides support for our result that more addiction leads to lower savings.
} 
detrimental health effects from addictive substances.

Despite the lower consumption of the addictive good when young, individuals will still derive a "high" from consumption of the addictive good when old. Thus, when old and an individual's health status is given, individuals will choose to consume more of the addictive good. In this manner, we find that although the overall level of consumption of addictive goods is lower when the accompanying health consequences are more severe, individuals will choose a steeper consumption path for addictive goods. They substitute consumption of the addictive good when young for better health and higher marginal utility when old (relative to the marginal utility of consumption of the addictive good when young)-this is why savings in the economy is higher, but consumption of the composite good will be lower when $\mathrm{v}_{0}$ is higher. Finally, we note that lifetime utility is lower when addiction results in worse health.

At this point, it is useful to make some remarks about the welfare implications of the addictive effects and detrimental health effects. Although our result may seem counter-intuitive initially, we find that individuals will obtain higher lifetime utility when individuals have a higher 'taste' for addiction. Recall that the addictive effect implies that, for a given addictive stock, old-age individuals will obtain more additional utility from consumption of the addictive good when old. In our numerical results, this is assumed to take place for a given level of adverse health consequences resulting from addiction. Thus, a higher value for the addictive effect implies that individuals will obtain a bigger "high" from addictive consumption when old. As a result, individuals will obtain a higher level of lifetime utility when the addictive effect is stronger.

We note that our numerical results also imply that when the adverse health consequences resulting from addiction are more severe, welfare in the economy is lower. A common view of 
addiction is that the bigger the "high" from the substance, the more severe are the consequences for one's health. In our framework, this would imply looking at an economy with higher values of both $\eta$ and $v_{0}$. If $v_{0}$ is sufficiently proportional to $\eta$, then "addiction" will be associated with lower aggregate welfare.

We next turn to the effects of other utility parameters. Higher values of $\alpha$ are associated with a larger consumption share of the composite good in agents' instantaneous utility, which leads to increased demand for the composite good. The decline in consumption of the addictive good when young implies that people will be healthier when old and therefore will choose to save more. As a result, productivity in the economy will be higher and the relative price of the addictive good is lower in economies with higher values of $\alpha$. Finally, higher values of $\rho$ imply that individuals discount the future more. As a result, people consume slightly more of the addictive good when young. They also consume a little bit less of the composite good when old.

In conclusion, we discuss the effects of productivity in the addictive goods sector. For any amount of labor input into the production of the addictive good, total supply increases. This is associated with a lower relative price of the addictive good and increased consumption by both the young and old. Finally, the lower price of the addictive good also generates an income effect so that consumption of the composite good is only slightly lower. The details of the remaining parameters are analogous.

\section{Peer Externality Effects of Addictive Behavior}

We go on to study a setting where there are peer externalities associated with consumption of the addictive good. In particular, we seek to simultaneously capture the role of peer influence for participation in addiction, as well as some of the external costs. In our model, 
we analyze the role of peer influence in the following way: when consumption of the addictive good in the economy is higher, individuals will obtain a higher marginal utility from their own consumption. As we will show, when peer influence plays a stronger role, total consumption of the addictive good will be higher and will have some important general equilibrium consequences. $^{11}$

Similarly, we are also able to capture some of the external costs of addiction. In particular, we attempt to capture some of the external aspects of addiction in terms of increased mortality. These external costs associated with addiction have been well documented, especially for the case of alcohol and drunk driving. For example, Kenkel (1993) reports that alcohol was responsible for as many as 24,000 deaths and over 554,000 injuries in motor vehicle accidents in 1986. There are additional negative health externalities as the result of second-hand smoke. We capture these external costs in terms of increased risk of mortality by assuming that individuals will obtain less overall utility when old as a result of consumption of addictive goods.

In our framework, we believe the most tractable manner in which to capture both aspects of peer externalities associated with addiction is through the accumulation of the addictive stock. Recall in the previous section, the addiction effect occurs since consumption when young raises the marginal utility of the addictive good when old, while the detrimental health effect stresses that accumulation of the addictive stock will have negative consequences for an individual's future utility. In a similar manner, we can capture both aspects of peer externalities (peer

\footnotetext{
${ }^{11}$ In particular, DeCicca, Kenkel, and Mathios (2002) find that there are significant differences in youth smoking behavior across racial and ethnic groups. This suggests that peer influence is important for studying the consumption of addictive goods and that it may vary between different types of addictive goods.
} 
influence and increased risk of mortality).

Recall that $S_{t+1}^{t}$ represents the stock of the addictive good accumulated by a member of generation $t$ in period $t+1$. Further, let $\bar{S}_{t+1}^{t}$ denote the average stock of the addictive good accumulated across the entire old generation at the beginning of period $t+1$. We then allow $v\left(S_{t+1}^{t}\right)$ from section II to depend on both an individual's consumption and a corresponding measure of aggregate consumption, given by $\bar{S}_{t+1}^{t}$. In this manner, we augment the function $v$ such that $v=v\left(S_{t+1}^{t}, \bar{S}_{t+1}^{t}\right)$. In particular, we write that $v=v\left(S_{t+1}^{t}, \bar{S}_{t+1}^{t}\right)=\left(1+v_{0}\left(S_{t+1}^{t}\right)^{\eta}\left(\bar{S}_{t+1}^{t}\right)^{\phi}\right)$. Thus, the higher the value of $\phi$, the stronger the role of peer influence in the consumption of addictive goods. That is, the larger the value of $\phi$, the higher the marginal utility from addiction when old. Due to the detrimental health effect (as captured by $v_{0}$ ), the extent of peer influence will also contribute to individuals receiving less utility from old-age consumption. ${ }^{12}$

The results of our numerical exercises below illustrate the general equilibrium effects of peer influence in the process of addiction in our model. In the below, we choose the same benchmark set of parameters as in Section IV. We examine the effects of peer externalities by looking at the results for different values of $\phi$.

\footnotetext{
${ }^{12}$ It is also plausible that consumption of addictive goods may directly affect an individual's productivity as initially studied by Fisher (1926), which could easily be captured in our framework. We could assume workers are endowed with a given amount of efficiency units of labor (which they supply inelastically). When individuals consume more alcohol, for example, the productivity of their labor will be lower, and therefore lost productivity could easily be captured in our model. Alternatively, we could capture the role of addiction in terms of additional government expenditures (such as through the criminal justice system and social programs) by assuming that the government must raise a given amount of funds which is proportional to aggregate consumption of the addictive good. Thus, tax revenues would need to be raised to finance these public expenditures resulting from addiction. Our model represents one of a number of possibilities for studying the external costs of addiction.
} 
(Insert Table 2 about here.)

We note that the effects of peer influence are in some ways similar to what is observed in terms of the addiction effect. The stronger the role of peer influence, the bigger the "high" that individuals obtain from consumption of the addictive good when old. This stimulates consumption of the addictive good in the economy and consequently raises the relative price of the addictive good. Due to the adverse health consequences resulting from addiction, individuals choose to save less. Although there is less savings in the economy, individuals choose to substitute from consumption of the addictive good when old towards the composite good due to the higher relative price of addictive goods. We also note that although the capital stock is lower, the increase in the relative price of the addictive good actually causes the wage rate in the economy to rise.

Finally, we would like to point out in this stylized case that welfare in the economy is higher when there is more of a role for peer influence since individuals obtain a bigger "high" from addictive consumption, while the adverse health consequences resulting from addiction remain the same. In the next section, however, we show that the peer externality in conjunction with the detrimental health effect implies that individuals will consume too much of the addictive good - this leads to social inefficiency and hence there is a role for public policy to play in correcting such external effects.

\section{Public Policy}

We now consider the possible effects of public policy in our economy. Our analysis is relatively simple. We examine the effects of a tax on the addictive good where the legal incidence of the tax is on the price paid by consumers. That is, $p_{t}=(1+\tau) p_{t}^{*}$ where $p_{t}^{*}$ is the 
price received by producers and $p_{t}$ is the price paid by consumers. We assume that tax revenues received by the government are directed towards spending which does not directly affect consumers' welfare.

Our focus is on conducting comparative steady-state analysis, that is, we examine how different levels of the tax rate on the addictive good affect steady-state allocations. We also want to draw some insights into the appropriate levels of taxes on addictive goods. To do this, we examine how different tax rates affect a representative young person's expected lifetime utility. It is important to bear in mind that the main purpose of our exercise is to study in positive and normative analyses the economics of a tax levied on addictive goods by highlighting distortions arising purely from the consumption-savings decision. That is, our study does not account for potential consequences via human capital or occupational choice decisions. ${ }^{13}$

More specifically, note that we have two sources of inefficiency in our economy and therefore a number of reasons for taxation of addictive goods. The first is that individuals do not take into account their effects on the productivity of the future generation when they make their savings decisions. That is, when individuals make decisions concerning addictive consumption, there will be adverse consequences for one's health. Due to the detrimental health effect, the current generation of young agents will save less since they will derive less overall utility from their old-age consumption. Thus, as a result of addiction, productivity in the economy will be lower (due to the lower capital stock).

The second distortion occurs due to the direct negative external consequences associated

\footnotetext{
${ }^{13}$ The reader is referred to Kenkel and Wang (2001) for an analysis focusing on the human capital and occupational choice aspects.
} 
with addiction - although a higher amount of consumption of the addictive good in society raises the marginal utility of consumption when old, there is also an increased risk of mortality for society as a whole. When $\bar{S}_{t+1}^{t}$ is higher, individuals will obtain less overall utility in when old. In this sense, individuals will not take into account how their consumption of the addictive good will have a negative impact on social welfare.

We begin by examining the effects of the tax on the addictive good in the benchmark model. Our numerical results are presented in the table below. Our benchmark set of parameters is the same as in Section IV. We first note that higher tax rates are associated with lower consumption of the addictive good among both the young and the old. Due to the decline in habit formation (from the tax when young), old-age consumption of the addictive good falls more than consumption when young. In this manner, our results are consistent with the viewpoint that higher taxes on addictive goods will reduce overall lifetime consumption. This occurs since individuals will consume less when young and thus one is less likely to acquire an addiction.

\section{(Insert Table 3 about here.)}

We find that there is a slight increase in the price received as a result of the tax. This is due to the general equilibrium consequences of the tax. We note that in our benchmark model, one of the main external consequences associated with addiction is that individuals choose to save less and therefore the future young will have a lower capital stock with which to work. Towards alleviating this distortion, we show that the addictive tax encourages capital formation. Due to the increase in taxes, individuals choose to become more healthy - this provides more incentives for individuals to save and therefore the capital stock is higher. Due to the increase in productive factors, the marginal product of labor will be higher in the composite goods sector 
and therefore total production will be higher. Thus, although there is less consumption of the addictive good as a result of the tax, there is a tendency for the its relative price to rise slightly since there will be less production in the addictive goods sector. Due to the increase in capital accumulation, we also see that the addiction tax raises the real gross domestic product in the economy $(p x+y)$.

Furthermore, we can find the economy's optimal tax rate. As illustrated in the table, much of the welfare gains from taxation stem from increased capital formation. We note that at sufficiently higher tax rates $(\tau \geq .05)$, the increase in savings in the economy resulting from higher taxes begins to diminish. Thus, although there is an increase in production of the composite good due to higher productivity, eventually these gains are not sufficient to cover the lost utility from consumption of the addictive good and welfare begins to decline with the higher tax rates. Consequently, for our benchmark set of parameters, we find that the optimal tax rate is approximately $\tau^{*}=6 \% .^{14}$

Notably, this result suggests that the government should impose a $6 \%$ tax on the addictive good, even in the absence of a peer-group externality or other adverse consequences and without accounting for the detrimental effects on human capital and occupational choice. Moreover, should the competing tax instrument be a distortionary labor or capital income tax, the tax incidence analysis would result in a much higher optimal sin tax rate. We can draw some

${ }^{14}$ Pogue and Stontz (1989) and Kenkel (1996) derive relatively simple formulas for the economy's optimal tax rate. While both papers exogenously impose demand schedules for different types of consumers of alcohol in partial equilibrium frameworks, we derive the total consumption of alcohol in the economy within a dynamic general equilibrium model of rational addiction. The additional considerations provide a richer perspective on the external costs of addiction, but we cannot solve the entire system analytically. Thus, in contrast, we solve for the optimal tax using our numerical results. 
additional insights on the effects of taxes in the economy by comparing their effects relative to the steady-state equilibrium allocation with no taxes $(\tau=0)$. To begin, we find that welfare in an economy with a tax rate of $18 \%$ is the same as when $\tau=0$. However, total gdp in the economy is slightly higher (about $1.1 \%$ ). The share of government revenues relative to total gdp is $2.2 \%$ when the tax rate is at $18 \%$.

We now extend our analysis to the case of peer externalities by considering two cases one with weak peer-group effects $(\phi=1 / 2)$ and another with strong peer-group effects $(\phi=1)$. Recall that peer externalities in our model come in two forms: on the one hand, peer influence raises the marginal utility of consumption, but also contributes to increased mortality. We note that although the higher tax rate will raise capital accumulation, it also lowers the marginal utility of consumption of the addictive good because individuals derive less utility from peer acceptance. Thus, in choosing the optimal (long-run) tax rate, society faces a "partyproductivity" trade-off - although a higher tax rate encourages more capital formation, it also lowers consumption of the addictive good. In addition, due to a "social multiplier" in consumption of the addictive good (in the case of peer externalities), there is reason to suspect that consumption will fall more when taxes are applied.

(Insert Tables 4 and 5 about here.)

We begin with the case where the role of peer influence is relatively minor $(\phi=1 / 2)$. As in the benchmark model, consumption of the addictive good is lower at each stage of the life cycle. We also see that old-age consumption falls more than youth consumption. In addition, the decline in old-age consumption is more significant than in the benchmark model. We also find the addictive tax encourages individuals to save more and that the increase in the capital stock is 
higher the stronger the peer externalities in consumption of the addictive good.

We conclude by discussing the implications of peer externalities for tax policy. In

general, we find that the stronger the peer externalities from consumption of addictive goods, the higher the optimal tax rate. In particular, we find the optimal tax rate is $8.7 \%$ when $\phi=1 / 2$ while it is higher at $9.5 \%$ when $\phi=1$. Again, this is due to the party-productivity tradeoff in our model and the presence of the peer-group effect suggests a higher optimal tax rate on the addictive good by up to $3.5 \%$. Eventually, the gains from increased capital formation are offset by the loss in utility when there is less consumption of addictive goods. In the case of $\phi=1 / 2$, we find that welfare in the economy at a tax rate of about $18 \%$ is the same as the $\tau=0$ case. The economy's total real income (gdp) is approximately $1.1 \%$ higher and the share of government revenue relative to gdp is around $2.2 \%$ when the tax rate is set at $18 \%$. When the peer externalities are stronger $(\phi=1)$, this rate rises to slightly above $20 \%$. Interestingly, the increase in total real income is around $1.1 \%$ higher than when $\tau=0$. Finally, we find the share of government revenue relative to gdp is almost $2.3 \%$ when the tax rate is at $20 \%$.

\section{Concluding Remarks}

In recent years, both the social and economic consequences of addiction have received much attention. As argued by many studies, the external consequences of an individual's consumption of addiction are likely to exceed the internal costs. Raising taxes on harmful substances such as alcohol or cigarettes will certainly deter individuals from participating in addictive behaviors and lower the external costs that arise from participation (such as drunk driving, criminal behavior, etc). A common concern with such an approach, however, is that such policies may lower social welfare. As discussed in Pogue and Stontz (1989), “...a tax on 
alcohol would reduce consumption indiscriminately...and therefore reduce the satisfaction experienced by millions of sensible drinkers without necessarily reducing the harm caused by a few excessive drinkers." Thus, the optimal excise tax should balance the reduction in external costs with the reduction in utility that will occur when individuals consume less of addictive commodities. This is particularly true when one considers that participation in consumption of these substances is a social activity.

In order to better understand the pattern of consumption of addictive goods, the social and economic consequences of addiction, and how to design public policy, this paper constructs a dynamic general equilibrium model of rational addiction. In particular, our two period overlapping generations structure allows us to clearly study consumption decisions simultaneous with savings, capital formation, and labor supply. This is particularly important since savings by the current young in our model directly determines next period's capital stock, and thereby productivity in the economy. We adopt a young individual's discounted lifetime utility as our welfare criterion. This is important in that, along with endogenous determination of the relative price of the addictive good, wages, and the interest rate, we are able to assess how various economic factors affect social welfare. Given these insights, we proceed to determine the optimal tax rate. In our benchmark model, we find the optimal tax balances the gains from increased capital formation against the loss in utility that occurs due to less consumption of addictive substances. When we consider that participation in the consumption of addictive goods, such as alcohol, are social activities with external consequences, we find that the optimal tax rate is higher.

We believe our framework can be extended in a number of ways to explore other 
remaining and important issues. Our current approach adopts the rational addiction framework along the lines of Becker and Murphy (1988) to study the general equilibrium consequences of addiction. As has been emphasized by a number of studies, there is evidence that consumption decisions of addictive goods may also be accompanied by a sense of regret as in Orhphanides and Zervos (1995), as well as time-inconsistency (Gruber and Koszegi, 2001). Thus, an important avenue for future research would be to extend the current setting to a three-period model in order to incorporate these additional aspects of intertemporal decision-making. In this manner, future research could provide additional insights into the patterns of consumption of addictive goods, along with their implications for savings decisions, and the optimal tax rate.

Another important extension will be to consider the general equilibrium implications of addiction by incorporating human capital choices, as well as other labor market implications such as job selection and the interactions with job search (following in the spirit of Kenkel and Wang, 2001, and Stewart, 2001). For example, we could consider the implications of human capital investment in our framework. Individuals, when young, make human capital choices where the opportunity cost of education involves foregone wages. In this manner, the negative health consequences of addictive will affect an individual's schooling effort and opportunities in the labor market. As a consequence, one may re-compute the optimal tax rate to be imposed on the addictive good and examine the consequences of the interactions between health and human capital accumulation, consumption and savings decisions, as well as economic welfare. 


\section{References}

Baumann, K.E. and S.T. Ennett (1996), “On the importance of peer influence for adolescent drug use: commonly neglected considerations," Addiction, 91(2), 185-198.

Beales, J.H. (1996), “The Determinants of Teenage Smoking Behavior,” mimeo, George Washington University.

Becker, G.S., M. Grossman, and K.M. Murphy (1994), “An Empirical Analysis of Cigarette Addiction," American Economic Review, 84(3), 396-418.

Becker, G.S. and K.M. Murphy (1988), “A Theory of Rational Addiction,” Journal of Political Economy, 96(4), 675-700.

Bloom, D.E., D. Canning, and B. Graham (2002), “Longevity and Life Cycle Savings,” NBER Working Paper \#8808.

Chaloupka, F.J. and K. Warner (2000), “The Economics of Smoking,” in Anthony Culyer and Joseph Newhouse, eds, Handbook of Health Economics, 1539-1628.

Cook, P.J. (1981), “The effect of liquor taxes on drinking, cirrhosis, and auto fatalities,” in M. Moore and D. Gerstein, eds., Alcohol and Public Policy: Beyond the Shadow of Prohibition. (National Academy of Sciences, Washington, D.C.), 255-285.

Cook, P.J. and G. Tauchen (1982), "The effect of liquor taxes on heavy drinking," Bell Journal of Economics, 13(2), 379-390.

Cook, P.J. and M. J. Moore (2000), “Alcohol,” in Anthony Culyer and Joseph Newhouse, eds, Handbook of Health Economics, 1539-1628.

Cook, P.J. and M.J. Moore (1993a), "Drinking and Schooling," Journal of Health Economics, $12,411-429$. 
Cook, P.J. and M.J. Moore (1993b), “Economic perspectives on alcohol-related violence,” in S.E. Martin, ed., Alcohol-Related Violence: Interdisciplinary Perspectives and Research Directions (National Institute on Alcohol Abuse and Alcoholism, NIH Publication No. 93-3496, Rockville, MD), 193-212.

Cook, P.J. and M.J. Moore (1994), “This Tax's for You: The Case for Higher Beer Taxes,” National Tax Journal, 559-573.

DeCicca, P., D. Kenkel, and A. Mathios (2000), "Racial Differences in the Determinants of Smoking Onset," Journal of Risk and Uncertainty, 21, 311-340.

DeCicca, P., D. Kenkel, and A. Mathios (2002), "Putting Out the Fires: Will Higher Taxes Reduce the Onset of Youth Smoking?” Journal of Political Economy, 110, 144-169.

Fisher, I. (1926), Prohibition at Its Worst (The MacMillan Company, New York).

Grossman, M. (1972), “On the Concept of Health Capital and the Demand for Health,” Journal of Political Economy, 80, 223-255.

Gruber, J. (2001), “The Economics of Tobacco Regulation,” mimeo, MIT.

Gruber, J. and B. Koszegi (2001), “A Theory of Government Regulation of Addictive Bads: Optimal Tax Levels and Tax Incidence for Cigarette Excise Taxation,” mimeo, MIT. Jones, A.M. (1994), "Health, Addiction, Social Interaction and the Decision to Quit Smoking," Journal of Health Economics, 13(1), 93-110.

Kenkel, D.S. (1991), "Health Behavior, Health Knowledge, and Schooling,” Journal of Political Economy, 99(2), 287-305.

Kenkel, D.S. (1993), “Do Drunk Drivers Pay Their Way? A Note on Optimal Penalties for Drunk Driving," Journal of Health Economics, 12, 137-149. 
Kenkel, D.S. (1996), "New Estimates of the Optimal Tax on Alcohol.” Economic Inquiry, 33(2), 296-319.

Kenkel, D.S. and P. Wang (1999), “Are Alcoholics in Bad Jobs?” in The Economic Analysis of Substance Use and Abuse, (ed. by F. Chaloupka, M. Grossman, W. Bickel and H. Saffer), NBER, University of Chicago Press, 251-278.

Kenkel, D.S. and P. Wang (2001), "Rational Addiction, Occupational Choice and Human Capital Accumulation," in The Economic Analysis of Substance Use and Abuse: The Experience of Developed Countries and Lessons for Developing Countries (edited by M. Grossman and C. Hsieh), Edwards-Elgar, 33-60.

Laux, F.L. (2000), “Addiction as a Market Failure: Using Rational Addiction Results to Justify Tobacco Regulation,” Journal of Health Economics, 19, 421-437.

Leibenstein, H. (1950), “Bandwagon, Snob, and Veblen Effects in the Theory of Consumers' Demand," Quarterly Journal of Economics, 64, 183-207.

Manning, W., L. Blumberg, and L. Moulton (1995), “The Demand for Alcohol: the differential response to price," Journal of Health Economics, 14(2), 123-148.

Manning, W.G., E.B. Keeler, J.P. Newhouse, E.M. Sloss, and J. Wasserman (1991), The Costs of Poor Health Habits, (Harvard University Press, Cambridge, MA).

Markowitz, S. and M. Grossman (2000), "The effects of beer taxes on physical child abuse," Journal of Health Economics, 19, 271-282.

Manning, W.G., E.B. Keeler, J.P. Newhouse, E.M. Sloss, and J. Wasserman, (1989), “The Taxes of Sin: Do Smokers and Drinkers Pay Their Way?", The Journal of the American Medical Association, 261(A3), 1604-1609. 
Mullahy, J. and J.L. Sindelar (1989), "Lifecycle effects of alcoholism on education, earnings, and occupation," Economic Inquiry, 26(2), 272-82.

Mullahy, J. and J.L. Sindelar (1991), "Gender differences in labor market effects of alcoholism," American Economic Review, 81(2), 161-165.

Mullahy, J. and J.L. Sindelar (1993), “Alcoholism, Work, and Income,” Journal of Labor Economics, 11(3), 494-520.

Norton, E.C., R.C. Lindroth, and S.T. Ennett (1998), “Controlling for Endogeneity of Peer Substance Use on Adolescent Alcohol and Tobacco Use," Health Economics, 7, 439-453.

Orphanides, A. and D. Zervos (1995), "Rational Addiction with Learning and Regret," Journal of Political Economy, 103, 739-758.

Pogue, T.F. and L.G. Stontz (1989), "Taxing to Control Social Costs: The Case of Alcohol," American Economic Review, 79(1), 235-243.

Reiss, A. J. and J.A. Roth (1993), Understanding and Preventing Violence. Washington, D.C.: National Academy Press, 1993.

Rice, D., E.J. MacKenzie and Associates, 1989, Cost of injury in the United States: A report to Congress, San Francisco, CA: Institute for Health and Aging, University of California and Injury Prevention Center, The Johns Hopkins University.

Rice, D.P., S. Kelman, L.S. Miller and S. Dunmeyer (1990), The Economic Costs of Alcohol and Drug Abuse and Mental Illness: 1985, Report submitted to the Office of Financing and Coverage Policy of the Alcohol, Drug Abuse, and Mental Health Administration, (U.S. Department of Health and Human Services, Institute for Health and Aging, University of California, San Francisco). 
Starr-McCluer, M. (1996), "Health Insurance and Precautionary Savings," American Economic Review, 86(1), 285-295.

Stewart, Jennifer M. (2001), “The Impact of Health Status on the Duration of Unemployment Spells and the Implications for Studies of the Impact of Unemployment on Health Status," Journal of Health Economics, 20, 781-96.

Viscusi, W. Kip (1995), "Cigarette Taxation and the Social Consequences of Smoking," in James Poterba, ed., Tax Policy and the Economy 13, Cambridge, MA: MIT Press, pp. 51-101. Yen, S.T. and A.M. Jones (1996), "Individual Cigarette Consumption and Addiction: A Flexible Limited Dependent Variable Approach," Health Economics, 5, 105-117. 


\section{Appendix}

$\underline{\text { Solve for labor allocation and output }}$

The second period budget constraint in the steady state becomes:

$$
c^{\prime}+p a^{\prime}=R k
$$

Using the wage equalization property, we can solve for $l$ as a function of $y$ alone,

$$
l=\frac{(1-\theta) y}{p B}
$$

Applying the production technology (2a), one can rewrite the capital efficiency condition (5c) as:

$$
R=\theta A k^{\theta-1} l^{1-\theta}
$$

This and the constant-returns property enable us to obtain: $R k=\theta y$, which together with (A1) yields (8a). By substituting (8a) into (A2), we get (8c). We then plug (8c) into the production technology for the addictive good to derive (8b).

$\underline{\text { Show that Walras' law holds }}$

In the steady state, the intertemporal budget constraint can be written as,

$$
p a+c+\frac{\left(c+p a^{\prime}\right)}{R}=w
$$

Substitute now (8b) to eliminate $x$ in the material balance condition for the addictive good to obtain:

$$
p a+p a^{\prime}=B p-(1-\theta) y
$$

which together with the material balance condition for the composite goods implies,

$$
(c+p a)+\left(c^{\prime}+p a^{\prime}\right)+k=B p+\theta y
$$


Further substitution for $\theta y$ from (8a) gives: $(c+p a)+k=B p$, which in conjunction with the capital efficiency condition and (8a) yields the intertemporal budget constraint (A4).

Express the system in a recursive manner to reduce to $3 \times 3$ subsystem.

From (8c), we already have $l$ in terms of $\left\{c, c^{\prime}, a, a^{\prime}, p\right\}$. Then, recall from (A3) that $R$ is a function of the capital-labor ratio alone. By the labor efficiency condition (5b), after imposing the steady-state, we have:

$$
\frac{k}{l}=\left[\frac{p B}{(1-\theta) A}\right]^{1 / \theta}
$$

Substituting (A7) into (A3) yields (9).

By the material balance condition for the composite and the addictive goods, we obtain:

$$
\begin{gathered}
R \theta c=(R-\theta) p a^{\prime}+(R(1-\theta)-\theta) c^{\prime} \\
(1-\theta) c^{\prime}+p a^{\prime}=\theta p(B-a)
\end{gathered}
$$

which can be used to solve for $c^{\prime}$ and $a^{\prime}$ in terms of $\{c, a$, and $p\}$, as in (11a) and (11b).

We next illustrate how the three remaining equations (6a)-(6c) jointly determine the endogenous variables in the system: $(c, p, a)$. Begin with the steady-state version of the firstorder condition describing old age consumption choices, (6b),

$$
c^{\prime}(c, p, a)=\frac{\alpha}{1-\alpha} p a^{\prime}(c, p, a)
$$

Next, recall the steady-state version of equation (6c), intertemporal choices for consumption of the composite good, after substituting for $U^{\prime} / U$ : 


$$
\left(\frac{a^{\prime}(c, p, a)}{a}\right)^{-(1-\alpha)(\sigma-1)} \frac{R(p)}{1+\rho} v(a)=\left(\frac{c^{\prime}(c, p, a)}{c}\right)^{1+\alpha(\sigma-1)}
$$

Equations (A10) and (A11) together enable us to derive:

$$
c=\left[\frac{\alpha}{1-\alpha} p\right]\left[\frac{1+\rho}{R(p)} \frac{\left(a^{\prime}(c, p, a)\right)^{\sigma}}{a^{(1-\alpha)(\sigma-1)} v(a)}\right]^{\frac{1}{1+\alpha(\sigma-1)}}
$$

Recall now the steady-state version of equation (6a) after substituting for $U^{\prime} / U$ :

$$
\frac{\alpha}{c}=\frac{1-\alpha}{p a}-\frac{v^{\prime}(a)}{(\sigma-1) p(1+\rho)}\left[\left(\frac{c^{\prime}(c, p, a)}{c}\right)^{\alpha}\left(\frac{a^{\prime}(c, p, a)}{a}\right)^{1-\alpha}\right]^{-(\sigma-1)}
$$

Utilizing the steady-state version of (6c) renders a version of (A13) which is more tractable:

$$
c^{\prime}(c, p, a)=\left[\left(\frac{1-\alpha}{p a}\right) c-\alpha\right] p(\sigma-1) R(p)\left(\frac{v(a)}{\eta v_{0}(a)^{\phi-1}}\right)
$$

Substituting (11a) and (11b) into (A11), (A12) and (A14) then yields the three fundamental equations (12a)-(12c) for the recursive $3 \times 3$ subsystem. 
Table 1:

Benchmark Equilibrium Outcomes and Sensitivity Analysis without Peer-Group Effects

\begin{tabular}{|l|c|l|l|l|l|l|l|l|l|l|l|}
\hline \multirow{2}{*}{} & \multirow{2}{*}{ Benchmark } & \multicolumn{2}{|c|}{$\eta$} & \multicolumn{2}{|c|}{$v_{0}$} & \multicolumn{2}{|c|}{$B$} & \multicolumn{3}{|c|}{$\alpha$} & \multicolumn{2}{|c|}{$\rho$} \\
\cline { 3 - 12 } & & 1.2 & 1.4 & 0.4 & 0.6 & 2.9 & 3.1 & 0.75 & 0.8 & 0 & 0 \\
\hline$a$ & $\mathbf{0 . 2 2 9}$ & 0.22 & 0.23 & 0.24 & 0.22 & 0.22 & 0.23 & 0.25 & 0.21 & 0.23 & 0.23 \\
\hline$a^{\prime}$ & $\mathbf{0 . 3 6 1}$ & 0.36 & 0.36 & 0.36 & 0.36 & 0.35 & 0.37 & 0.39 & 0.33 & 0.36 & 0.36 \\
\hline$c$ & $\mathbf{1 . 3 2}$ & 1.32 & 1.32 & 1.31 & 1.33 & 1.32 & 1.32 & 1.31 & 1.33 & 1.32 & 1.32 \\
\hline$c^{\prime}$ & $\mathbf{1 . 3 1}$ & 1.32 & 1.31 & 1.31 & 1.32 & 1.31 & 1.31 & 1.27 & 1.35 & 1.31 & 1.31 \\
\hline$x$ & $\mathbf{0 . 5 9}$ & 0.59 & 0.59 & 0.6 & 0.58 & 0.57 & 0.61 & 0.64 & 0.54 & 0.59 & 0.59 \\
\hline$y$ & $\mathbf{4 . 2 3}$ & 4.25 & 4.22 & 4.22 & 4.25 & 4.23 & 4.24 & 4.24 & 4.23 & 4.24 & 4.23 \\
\hline$L$ & $\mathbf{0 . 8 0 3}$ & 0.81 & 0.8 & 0.8 & 0.81 & 0.8 & 0.8 & 0.79 & 0.82 & 0.8 & 0.8 \\
\hline$P$ & $\mathbf{1 . 0 5}$ & 1.06 & 1.05 & 1.06 & 1.05 & 1.09 & 1.02 & 1.08 & 1.03 & 1.06 & 1.05 \\
\hline$R$ & $\mathbf{1 . 0 6}$ & 1.06 & 1.06 & 1.06 & 1.06 & 1.06 & 1.06 & 1.02 & 1.1 & 1.06 & 1.06 \\
\hline$w$ & $\mathbf{3 . 1 6}$ & 3.17 & 3.16 & 3.17 & 3.16 & 3.16 & 3.16 & 3.24 & 3.09 & 3.16 & 3.16 \\
\hline$\Omega$ & $\mathbf{- 2 . 1 8}$ & -2.2 & -2.2 & -2.2 & -2.2 & -2.2 & -2.2 & -2.3 & -2.1 & -2.2 & -2.2 \\
\hline$c^{\prime} / c$ & $\mathbf{0 . 9 9 4}$ & 1 & 0.99 & 1 & 0.99 & 1 & 0.99 & 0.97 & 1.02 & 1 & 0.99 \\
\hline$a^{\prime} / a$ & $\mathbf{1 . 5 8 1}$ & 1.62 & 1.55 & 1.48 & 1.68 & 1.56 & 1.6 & 1.57 & 1.59 & 1.59 & 1.58 \\
\hline$k$ & $\mathbf{1 . 6}$ & 1.61 & 1.6 & 1.6 & 1.6 & 1.6 & 1.6 & 1.66 & 1.54 & 1.61 & 1.6 \\
\hline$p x+y$ & $\mathbf{4 . 8 6}$ & 4.86 & 4.85 & 4.85 & 4.86 & 4.86 & 4.86 & 4.94 & 4.78 & 4.86 & 4.85 \\
\hline$y$ & $\mathbf{0 . 8 7 2}$ & 0.87 & 0.87 & 0.87 & 0.87 & 0.87 & 0.87 & 0.86 & 0.89 & 0.87 & 0.87 \\
\hline$p x+y$ & & & & & & & & & & & \\
\hline
\end{tabular}

Notes: The benchmark parameter values are: $\eta=1.3, v_{0}=0.5, B=3, \theta=0.4, \alpha=0.775, \sigma=2$, $A=4$, and $\rho=0.035$, in the absence of peer-group effects $(\phi=0)$. Equilibrium outcomes in the benchmark case are in bold. 
Table 2:

Equilibrium Outcomes in the Presence of Peer-Group Effects

\begin{tabular}{|l|l|l|l|l|l|}
\hline \multirow{2}{*}{} & \multicolumn{5}{|c|}{$\phi$} \\
\cline { 2 - 6 } & \multicolumn{1}{|c|}{0} & \multicolumn{1}{|c|}{0.25} & \multicolumn{1}{c|}{0.5} & \multicolumn{1}{c|}{0.75} & \multicolumn{1}{c|}{1} \\
\hline$a$ & 0.229 & 0.251 & 0.269 & 0.283 & 0.295 \\
\hline$a^{\prime}$ & 0.361 & 0.359 & 0.356 & 0.354 & 0.353 \\
\hline$c^{\prime}$ & 1.32 & 1.31 & 1.3 & 1.29 & 1.28 \\
\hline$x$ & 1.31 & 1.3 & 1.3 & 1.29 & 1.29 \\
\hline$y$ & 0.59 & 0.609 & 0.625 & 0.638 & 0.648 \\
\hline$L$ & 4.23 & 4.21 & 4.19 & 4.17 & 4.15 \\
\hline$P$ & 0.803 & 0.797 & 0.792 & 0.787 & 0.784 \\
\hline$R$ & 1.05 & 1.06 & 1.06 & 1.06 & 1.06 \\
\hline$w$ & 1.06 & 1.06 & 1.05 & 1.05 & 1.05 \\
\hline$\Omega$ & 3.16 & 3.17 & 3.17 & 3.18 & 3.18 \\
\hline$c^{\prime} / c$ & -2.18 & -2.16 & -2.14 & -2.13 & -2.12 \\
\hline$a^{\prime} / a$ & 0.994 & 0.997 & 1 & 1 & 1 \\
\hline$k$ & 1.58 & 1.43 & 1.33 & 1.25 & 1.2 \\
\hline$p x+y$ & 1.6 & 1.6 & 1.59 & 1.59 & 1.58 \\
\hline$y$ & 4.86 & 4.85 & 4.85 & 4.84 & 4.84 \\
\hline$p x+y$ & 0.872 & 0.867 & 0.864 & 0.861 & 0.858 \\
\hline
\end{tabular}

Notes: All other parameters are at their benchmark values. 
Table 3:

Sin Tax and Equilibrium Outcomes without Peer-Group Effects $(\phi=0)$

\begin{tabular}{|c|c|c|c|c|c|}
\hline & \multicolumn{5}{|c|}{$\tau(\%)$} \\
\hline & 0 & 5 & 10 & 15 & 20 \\
\hline$a$ & 0.229 & 0.223 & 0.218 & 0.213 & 0.208 \\
\hline$a^{\prime}$ & 0.361 & 0.347 & 0.334 & 0.322 & 0.31 \\
\hline$c$ & 1.32 & 1.33 & 1.34 & 1.35 & 1.36 \\
\hline$c^{\prime}$ & 1.31 & 1.32 & 1.33 & 1.34 & 1.35 \\
\hline$x$ & 0.59 & 0.57 & 0.552 & 0.534 & 0.518 \\
\hline$y$ & 4.23 & 4.27 & 4.3 & 4.34 & 4.37 \\
\hline$L$ & 0.803 & 0.81 & 0.816 & 0.822 & 0.827 \\
\hline$P$ & 1.05 & 1.11 & 1.16 & 1.21 & 1.27 \\
\hline$P^{*}$ & 1.05 & 1.05 & 1.06 & 1.06 & 1.06 \\
\hline$R$ & 1.06 & 1.06 & 1.06 & 1.06 & 1.06 \\
\hline$w$ & 3.16 & 3.16 & 3.16 & 3.17 & 3.17 \\
\hline$\% \Delta \Omega$ & 0 & 0.0165 & 0.00321 & -0.0355 & -0.0959 \\
\hline$c^{\prime} / c$ & 0.994 & 0.995 & 0.995 & 0.996 & 0.996 \\
\hline$a^{\prime} / a$ & 1.58 & 1.56 & 1.53 & 1.51 & 1.49 \\
\hline$k$ & 1.6 & 1.62 & 1.63 & 1.64 & 1.66 \\
\hline$p x+y$ & 4.86 & 4.87 & 4.89 & 4.9 & 4.91 \\
\hline$\frac{y}{p x+y}$ & 0.872 & 0.877 & 0.881 & 0.885 & 0.889 \\
\hline$T R$ & 0 & 0.03 & 0.058 & 0.085 & 0.109 \\
\hline
\end{tabular}

Notes: The optimal sin tax rate is approximately $\tau^{*}=6 \%$. 
Table 4:

Sin Tax and Equilibrium Outcomes with Weak Peer-Group Effects $(\phi=1 / 2)$

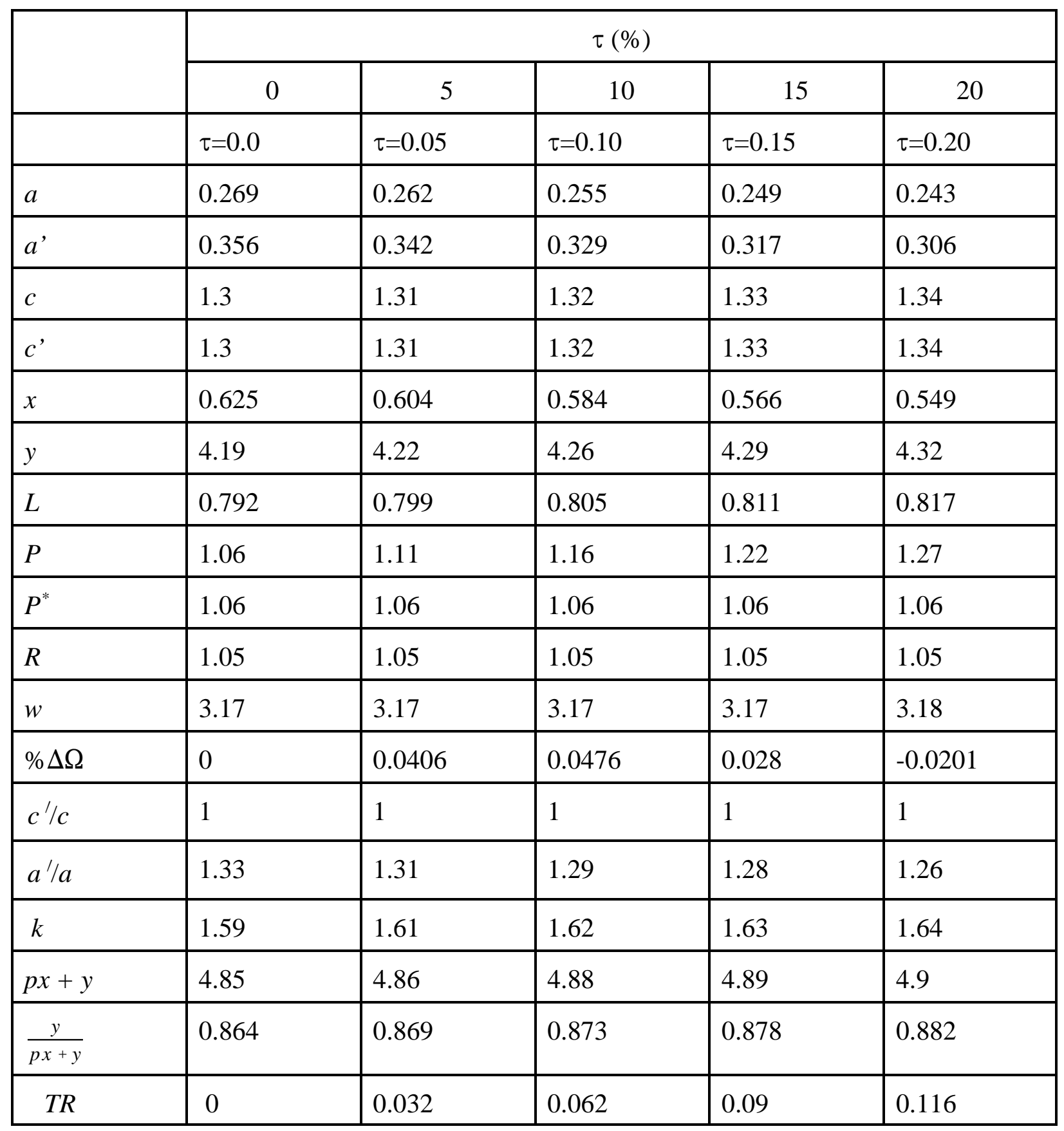

Notes: The optimal sin tax rate is approximately $\tau^{*}=8.7 \%$. 
Table 5:

Sin Tax and Equilibrium Outcomes with Strong Peer-Group Effects $(\phi=1)$

\begin{tabular}{|c|c|c|c|c|c|}
\hline & & & $\tau(\%$ & & \\
\hline & 0 & 5 & 10 & 15 & 20 \\
\hline & $\tau=0.0$ & $\tau=0.05$ & $\tau=0.10$ & $\tau=0.15$ & $\tau=0.20$ \\
\hline$a$ & 0.295 & 0.287 & 0.279 & 0.272 & 0.265 \\
\hline$a^{\prime}$ & 0.353 & 0.339 & 0.339 & 0.324 & 0.304 \\
\hline$c$ & 1.28 & 1.3 & 1.3 & 1.32 & 1.33 \\
\hline$c^{\prime}$ & 1.29 & 1.3 & 1.3 & 1.32 & 1.33 \\
\hline$x$ & 0.648 & 0.626 & 0.606 & 0.586 & 0.568 \\
\hline$y$ & 4.15 & 4.19 & 4.26 & 4.26 & 4.29 \\
\hline$L$ & 0.784 & 0.791 & 0.799 & 0.805 & 0.811 \\
\hline$P$ & 1.06 & 1.11 & 1.18 & 1.22 & 1.27 \\
\hline$P^{*}$ & 1.06 & 1.06 & 1.06 & 1.06 & 1.06 \\
\hline$R$ & 1.05 & 1.05 & 1.05 & 1.05 & 1.05 \\
\hline$w$ & 3.18 & 3.18 & 3.18 & 3.18 & 3.18 \\
\hline$\% \Delta \Omega$ & 0 & 0.0491 & 0.0623 & 0.0439 & 0 \\
\hline$c^{\prime} / c$ & 1 & 1 & 1 & 1 & 1 \\
\hline$a^{\prime} / a$ & 1.2 & 1.18 & 1.17 & 1.16 & 1.15 \\
\hline$k$ & 1.58 & 1.6 & 1.61 & 1.62 & 1.64 \\
\hline$p x+y$ & 4.84 & 4.85 & 4.87 & 4.88 & 4.9 \\
\hline$\frac{y}{p x+y}$ & 0.858 & 0.863 & 0.868 & 0.873 & 0.877 \\
\hline$T R$ & 0 & 0.033 & 0.064 & 0.093 & 0.12 \\
\hline
\end{tabular}

Notes: The optimal sin tax rate is approximately $\tau^{*}=9.5 \%$. 